\title{
Post Cataract Surgery Refractive Error in Myopic Patients Using SRK/T Versus Holladay 1 Formula for IOL Power Calculation
}

Sidra Anwar, Atif Mansoor Ahmad, Irum Abbas, Zyeima Arif

Pak J Ophthalmol 2019, Vol. 35, No. 2

See end of article for authors affiliations

Correspondence to:

Dr. Sidra Anwar

Trainee Registrar

Department of Ophthalmology,

Federal Postgraduate Medical

Institute/Shaikh Zayed Hospital

Lahore

Email:sidraanwar@gmail.com
Purpose: To compare post-operative mean refractive error with SandersRetzlaff-Kraff/theoretical (SRK-T) and Holladay 1 formulae for intraocular lens $(\mathrm{IOL})$ power calculation in cataract patients with longer axial lengths.

Study Design: Randomized controlled trial.

Place and Duration of Study: Department of Ophthalmology, Shaikh Zayed Hospital Lahore from 01 January 201701 January, 2018.

Material and Methods: A total of 80 patients were selected from Ophthalmology Outdoor of Shaikh Zayed Hospital Lahore. The patients were randomly divided into two groups of 40 each by lottery method. IOL power calculation was done in group A using SRK-T formula and in group B using Holladay1 formula after keratomery and A-scan. All patients underwent phacoemulsification with foldable lens implantation. Post-operative refractive error was measured after one month and mean error was calculated and compared between the two groups.

Results: Eighty cases were included in the study with a mean age of $55.8 \pm 6.2$ years. The mean axial length was $25.63 \pm 0.78 \mathrm{~mm}$, and the mean keratometric power was $43.68 \pm 1.1 \mathrm{D}$. The mean post-operative refractive error in group $A$ $(\mathrm{SRK} / \mathrm{T}$ ) was $+0.36 \mathrm{D} \pm 0.33 \mathrm{D}$ and in group $\mathrm{B}$ (Holladay 1 ) it was $+0.68 \pm 0.43$. The Mean Error in group A was $+0.37 \mathrm{D} \pm 0.31 \mathrm{D}$ as compared to $+0.69 \mathrm{D} \pm 0.44 \mathrm{D}$ in group B.

Conclusion: SRK/T formula is superior to Holladay 1 formula for cases having longer axial lengths.

Key words: Phacoemulsification, intraocular lens power, longer axial length, biometry.

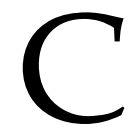

ataract and refractive errors are the leading causes of reversible blindness in the world ${ }^{1-3}$. In a study 4 it was found that one fifth $(20.9 \%)$ of the adult Pakistani population suffers from cataract. According to the Pakistan National Blindness and Visual Impairment Survey ${ }^{5}$ cataract remains the leading cause of blindness in Pakistani population. In all cases of uncomplicated cataract, intraocular lens implantation after phacoemulsification is the treatment of choice ${ }^{6-8}$ and emmetropia is the refractive target in most patients 9 . Achievement of desired postoperative refraction is a better measure of surgeon skill than the post-operative visual acuity ${ }^{10}$ which is also dependent on retinal and optic nerve status 9 . The post-operative refractive outcome of surgery depends not only on surgeon factors, site and type of lens implanted but most of all on accurate pre-operative biometry ${ }^{11-14}$. The major source of error $(35.5 \%)$ in 
biometry is the inaccuracy in the prediction of IOL power calculation formulae. The calculation of the dioptric power of an intraocular implant has evolved over the past few decades such that there are multiple calculation formulae giving variable results in different axial length ranges. Aristodemou et all5 cited the Hoffer $Q$ formulae being most accurate for axial lengths below $21.5 \mathrm{~mm}$ and SRK/T for those above 26 $\mathrm{mm}$. There was no statistical difference in accuracy of different formulae in the medium axial length range. Multiple studies have shown variable accuracy for different formulae in the longer axial length range with best results found with Haigis ${ }^{16-18}$, Holladay $1^{16,19}$ and SRK/T20.

There is high prevalence of axial myopia (longer axial length) in Pakistan ${ }^{21}$ and all over the world ${ }^{22}$. With recent advances in surgical and biometric techniques, post-operative emmetropia in previously myopic patients has become not only desirable but also achievable.

This study is designed to compare the accuracy of prediction of two formulae by comparing the postoperative mean refractive error in the two groups of patients. Holladay 1 and SRK/T have previously been studied and found to give good results in multiple studies comparing them with other formulae, but these have not been compared with each other in a subset of Pakistani population with longer axial lengths. Currently, these formulae are two of the most widely used formulae locally. Therefore, it is important to test their accuracy of prediction in all ranges of axial lengths, with the aim to define the formula preference in non-average axial length groups.

\section{MATERIAL AND METHODS}

This was a randomized controlled trial conducted at the Department of Ophthalmology, Shaikh Zayed Hospital, Lahore over a period of one year starting from 01 January, 2017. A total of 80 eyes having cataract, with axial length falling between $24.5 \mathrm{~mm}$ and $27 \mathrm{~mm}$ were selected through non-probability consecutive sampling. Patients of both genders in the age range of 40-70 years having cataract for more than 6 months and falling in the desired axial length range were included. Patients were divided randomly into two equal groups, A and B by lottery method. After informed consent was taken, keratometric readings of all subjects were taken by a single operator using automated keratometer. A-scan biometry using immersion technique was used to measure the axial length of the eye to be operated upon. These keratometric readings and axial length measurements were entered in the Alcon Accuscan (software version 1.15). The power of the intraocular lens implant to be used was calculated by using SRK/T formula and Holladay 1 formula in group A and B respectively. All the patients underwent phacoemulsification with foldable intraocular lens implant done by single surgeon with $3.2 \mathrm{~mm}$ incision given at 10-12 o'clock. Mean refractive error was defined as the difference between the value predicted by formulae and the actual postoperative refractive errors calculated after one month of surgery by auto refractometer and confirmed by retinoscopy and converted to spherical equivalent.The collected data was entered into SPSS version 17. Values were recorded as mean \pm SD of quantitative variables like age, axial length and mean refractive errors. Qualitative data like gender was presented in the form of frequency and percentages. Independent sample t-test was used to compare mean refractive error in both groups. $\mathrm{P}$ value $\leq 0.05$ was considered as significant. Data was stratified for age, gender and axial length to address the effect modifiers. Post-stratification independent sample $t$ test was used to check the significance with p-value $\leq$ 0.05 significant.

\section{RESULTS}

Eighty eyes of eighty subjects were included in the study, out of which $48(60 \%)$ were male and $32(40 \%)$ were female patients. Twenty five $(31.25 \%)$ males were included in Group A and $23(28.75 \%)$ in group B, while $15(18.75 \%)$ females were placed in group A as compared to $17(21.25 \%)$ in group B. Their ages ranged from 46 years to 70 years with a mean of $55.8 \pm 6.2$ years (Table 1).

Table 1: Distribution of Patients by Gender.

\begin{tabular}{|llcc|}
\hline Sex & & Frequency (n) & Percentage \% \\
\hline \multirow{3}{*}{ Male } & Group A & 25 & $31.25 \%$ \\
& Group B & 23 & $28.75 \%$ \\
& Total & 48 & $60 \%$ \\
& Group A & 15 & $18.75 \%$ \\
& Group B & 17 & $21.25 \%$ \\
& Total & 32 & $40 \%$ \\
\hline
\end{tabular}

The mean axial length was $25.63 \pm 0.78 \mathrm{~mm}$, with a minimum of $24.55 \mathrm{~mm}$ and maximum of $27 \mathrm{~mm}$. Fifty five $(68.75 \%)$ of the patients had an axial length $\leq 26$ 
$\mathrm{mm}$, whereas $25(31.25 \%)$ had axial length greater than $26 \mathrm{~mm}$. Group A showed a mean axial length of 25.61 $\pm 0.74 \mathrm{~mm}$ and group $\mathrm{B}$ had a mean of $25.64 \pm 0.82$ $\mathrm{mm}$. The $\mathrm{p}$ value $(0.376)$ was found to be insignificant (Table 2).

Table 2: Distribution of Patients According To Axial Length.

\begin{tabular}{|lcccc|}
\hline $\begin{array}{l}\text { Axial Length } \\
(\mathbf{m m})\end{array}$ & Mean & SD & Range & p value \\
\hline Overall & 25.63 & 0.78 & $24.55-27$ & \\
Group A & 25.61 & 0.75 & $24.56-27$ & 0.376 \\
Group B & 25.64 & 0.82 & $24.55-27$ & \\
\hline
\end{tabular}

Postoperative mean refractive error described in terms of the spherical equivalent ranged from $-0.25 \mathrm{D}$ to $+1.75 \mathrm{D}$ with a mean of $+0.52 \mathrm{D} \pm 0.41 \mathrm{D}$. Group $\mathrm{A}$ showed a mean of $+0.36 \mathrm{D} \pm 0.33 \mathrm{D}$ and group $\mathrm{B}$ had a mean of $+0.68 \pm 0.43$ (Table 3 ). The $p$ value according to independent sample t-test was 0.087 (> $0.05=$ insignificant).

The Mean Refractive Error (ME) showed an overall mean value of $+0.53 \pm 0.41 \mathrm{D}$. The mean refractive error among different patients ranged from a minimum of $-0.23 \mathrm{D}$ to a maximum of $+1.88 \mathrm{D}$. Group $\mathrm{A}(\mathrm{SRK} / \mathrm{T})$ had a mean value of $\mathrm{ME}$ equal to $+0.37 \mathrm{D} \pm$ $0.31 \mathrm{D}$, ranging from $-0.23 \mathrm{D}$ to $+0.89 \mathrm{D}$. The other group, $\mathrm{B}$ (Holladay 1 ) had a mean value of $\mathrm{ME},+0.69$ $\mathrm{D} \pm 0.44 \mathrm{D}$, ranging from +0.01 to +1.88 . The above data showed that Holladay 1 formula has a tendency to give slightly hyperopic results and the $p$ value $(p=0.03)$ was found to be significant (Table 4$)$.

Table 3: Distribution of Patients According To PostOperative Spherical Equivalent.

\begin{tabular}{|lcc|}
\hline $\begin{array}{l}\text { Post-op Spherical } \\
\text { Equivalent }\end{array}$ & Mean \pm SD & p value \\
\hline Overall & $+0.52 \pm 0.41 \mathrm{D}$ & \\
Group A & $+0.36 \pm 0.33 \mathrm{D}$ & 0.087 \\
Group B & $+0.68 \pm 0.43 \mathrm{D}$ & \\
\hline
\end{tabular}

The mean of ME of males in group A was $+0.41 \pm$ $0.33 \mathrm{D}$ and for group $\mathrm{B}$ it was $+0.65 \pm 0.36 \mathrm{D}$. The difference was seen to be insignificant $(p=0.473)$. Whereas, the females in group $A$ showed a Mean refractive error $(\mathrm{ME})$ of $+0.30 \pm 0.29 \mathrm{D}$ and those in group $\mathrm{B}$ had $\mathrm{ME}$ equal to $+0.73 \pm 0.54 \mathrm{D}$ with the $\mathrm{p}$ value $(0.031)$ found to be significant (Table 5).

Table 4: Comparison of Patients by Mean Refractive Error between Both Groups.

\begin{tabular}{|c|c|c|c|c|}
\hline & $\begin{array}{l}\text { Mean of ME (Mean } \\
\text { Refractive Error) }\end{array}$ & Standard deviation & $\begin{array}{c}\text { Standard Error of } \\
\text { Mean }\end{array}$ & p value \\
\hline Group A & 0.37 & 0.31 & 0.049 & \multirow{2}{*}{0.03} \\
\hline Group B & 0.69 & 0.44 & 0.0697 & \\
\hline
\end{tabular}

Table 5: Stratification of Data by Gender and Mean Refractive Error.

\begin{tabular}{|lcccc|}
\hline \multirow{2}{*}{ Gender } & Groups & Mean Refractive Error (ME) & Mean \pm SD & p value \\
\hline \multirow{2}{*}{ Male } & A & 25 & $+0.41 \pm 0.33 \mathrm{D}$ & 0.473 \\
& B & 23 & $+0.65 \pm 0.36 \mathrm{D}$ & \multirow{2}{*}{0.031} \\
Female & A & 15 & $+0.30 \pm 0.29 \mathrm{D}$ & $+0.73 \pm 0.54 \mathrm{D}$ \\
\end{tabular}

Table 6: Stratification of Data by Age and Mean Refractive Error.

\begin{tabular}{|c|c|c|c|c|}
\hline \multirow{2}{*}{ Age (years) } & \multirow{2}{*}{ Groups } & \multicolumn{2}{|c|}{ Mean Refractive Error (ME) } & \multirow{2}{*}{ p value } \\
\hline & & $\mathbf{n}$ & Mean \pm SD & \\
\hline \multirow{2}{*}{$40-55$} & A & 23 & $+0.36 \pm 0.32 \mathrm{D}$ & \multirow{2}{*}{0.82} \\
\hline & B & 18 & $+0.62 \pm 0.34 \mathrm{D}$ & \\
\hline \multirow{2}{*}{$56-70$} & A & 17 & $+0.38 \pm 0.32 \mathrm{D}$ & \multirow{2}{*}{0.029} \\
\hline & B & 22 & $+0.73 \pm 0.51 \mathrm{D}$ & \\
\hline
\end{tabular}

Pakistan Journal of Ophthalmology
Patients were divided into two groups based on age. The younger group (40-55 years) had a mean ME of $+0.36 \pm 0.32 \mathrm{D}$ in group $\mathrm{A}$ and $+0.62 \pm 0.34 \mathrm{D}$ in group $\mathrm{B}$, with an insignificant $\mathrm{p}$ value (0.82). In comparison, the older group showed a mean ME of $+0.38 \pm 0.32 \mathrm{D}$ 
in group $\mathrm{A}$ and $+0.73 \pm 0.51 \mathrm{D}$ in group $\mathrm{B}$. The difference in Mean Refractive Error in the two groups in the older aged individuals was significant $(p=0.029)$ (Table 6).

Two groups based on axial length were made and cases were divided accordingly. The subjects with comparatively shorter axial lengths $(24.5-25.5 \mathrm{~mm})$ falling in group A (SRK/T formula) showed a mean refractive error of $+0.35 \pm 0.30 \mathrm{D}$ and those in group B (Holladay 1) had a Mean refractive error of $+0.50 \pm 0.34 \mathrm{D}$, with an insignificant $p$ value(0.53). In the group with longer axial lengths (25.51-27 $\mathrm{mm}$ ) Group A individuals had a mean refractive error of $+0.40 \pm 0.36 \mathrm{D}$ as compared to $+1.04 \pm 0.40 \mathrm{D}$ in group B. With a $\mathrm{p}$ value of 0.98 , the difference between the two groups was seen to be insignificant (table 7).

\section{DISCUSSION}

This study was designed to compare the error in the refractive outcome of patients having longer axial lengths, while using two different biometric formulas (SRK/T and Holladay 1). It was found that there was a significant difference in the post-operative mean error among the two groups with Holladay 1 formulae giving slightly greater hyperopic results.The cases were stratified into subgroups based on gender, age and axial length and it was found that the Mean Refractive Error was significantly higher in female and older aged individuals in Group B (Holladay 1), but the difference in mean refractive error in the subgroups of axial lengths was insignificant. These results are consistent with previous studies. Bang et $\mathrm{al}^{17}$ found SRK/T formulae to be superior to Holladay 1 in longer axial lengths. El-Nafees et al20 similarly concluded that SRK/T gave the lowest mean error, but their results were not significant. These two studies were limited by their sample size. The most extensive study as yet done by Aristodemou et al15 found SRK/T formula to have lowest Mean Refractive Errors for longer axial lengths with significant differences for axial length longer than $27 \mathrm{~mm}$. In contrast to our results, Mitra et $\mathrm{al}^{19}$, in their retrospective study found Holladay 1 to be superior to SRK/T for individuals with longer axial lengths. This study as well as other studies that have been conducted is limited by their small sample size. Other limiting factors in this study were the small range of axial lengths studied and small number or formulae being compared. There is need for more comprehensive studies to be conducted in the future that incorporate a greater number of cases and a broader range of axial lengths and biometric formulae.

\section{CONCLUSION}

This study has shown SRK/T formula for be superior to Holladay 1 formula for cases having longer axial lengths, with a significantly smaller Mean Refractive Error. To get more statistically significant results, more comprehensive studies need to be conducted on this subject.

Conflict of interest: none.

\section{Author's affiliation}

Dr. Sidra Anwar

MBBS,

Trainee Registrar

Department of Ophthalmology, Sheikh Zayed Hospital, Lahore.

Dr. Atif Mansoor Ahmad

MBBS, FCPS, FRCS,

Associate Professor

Department of Ophthalmology, Sheikh Zayed Hospital, Lahore.

Dr. Irum Abbas

MBBS, FCPS,

Assistant Professor

Department of Ophthalmology, Sheikh Zayed Hospital, Lahore.

Dr. Zyeima Arif

MBBS,

Medical Officer

Department of Ophthalmology, Sheikh Zayed Hospital, Lahore. 


\section{Role of Authors}

\section{Dr. Sidra Anwar}

Data collection, compilation, writing the manuscript

Dr. Atif Mansoor Ahmad

Analysis, critical review, interpretation of results

Dr. Irum Abbas

Literature review, critical review

Dr. Zyeima Arif

Literature review

\section{REFERENCES}

1. Jonas JB , George R, Asokan R, Flaxman SR, Keeffe J, Leasher $\mathbf{J}$ et al. Prevalence and causes of vision loss in Central and South Asia: 1990-2010. Br J Ophthalmol. 2014 May; 98 (5): 592-8.

2. Khairallah $M$, Kahloun $R$, Flaxman SR, Jonas JB, Keeffe J, Leasher J, et al. Prevalence and causes of vision loss in North Africa and the Middle East:19902010. Br J Ophthalmol. 2014 May; 98 (5): 605-11.

3. Keeffe J , Taylor HR, Fotis K, Pesudovs K, Flaxman SR, Jonas JB, et al. Prevalence and causes of vision loss in Southeast Asia and Oceania: 1990-2010. Br J Ophthalmol. 2014 May; 98 (5): 586-91.

4. Shah SP, Dineen B, Jadoon Z, Bourne R, Khan MA, Johnson GJ, et al. Lens opacities in adults in Pakistan: prevalence and risk factors. Ophthalmic Epidemiol. 2007 Nov; 14 (6): 381-9.

5. Dineen B, Bourne RR, Jadoon Z, Shah SP, Khan MA, Foster A, et al. Causes of blindness and visual impairment in Pakistan. The Pakistan national blindness and visual impairment survey. Br J Ophthalmol. 2007 Aug; 91 (8): 1005-10.

6. Spiteri AV, Aggarwal R, Kersey TL, Sira M, Benjamin L, Darzi AW, et al. Development of virtual reality training curriculum for phacoemulsification surgery. Eye (Lond) 2013; 10: 1038.

7. Schriefl SM, Stifter E, Menapace R. Impact of low versus high fluidic settings of the efficacy and safety of phacoemulsification. Acta Ophthalmol. 2013; 92 (6).

8. Joseph S, Ravilla T, Bassett K. Gender issues in a cataract surgical population in South India. Ophthalmic Epidemiol. 2013; 20 (2): 96-101.

9. Moshirfar M, McCaughey MV, Santiago-Caban L. Corrective Techniques and Future Directions for Treatment of Residual Refractive Error Following Cataract Surgery. Expert Rev Ophthalmol. 2014; 9 (6): 529537.

10. Simon SS, Chee YE, Haddadin YE et al. Achieving
Target Refraction after Cataract Surgery. Ophthalmology; 121 (2): 440-444.

11. Sahin A, Hamrah P. Clinically relevant biometry. Curr Opin Ophthalmol. 2012; 23 (1): 47-53.

12. Sheard R. Optimising biometry for best outcomes in cataract surgery. Eye (Lond). 2014; 28 (2): 118-125.

13. Wang J K, Hu C Y, Chang S W. Intraocular lens power calculation using the IOL Master and various formulas in eyes with long axial length. Int J Ophthalmol. 2013 April; 6 (2): 150-4.

14. Reitblat O, Assia EI, Kleinmann G, Levy A, Barrett GD, Abulafia A. Accuracy of predicted refraction with multifocal intraocular lenses using two biometry measurement devices and multiple intraocular lens power calculation formulas. Clin Experiment Ophthalmol. 43: 328-334.

15. Aristodemou P, Cartwright NEK, Sparrow JM, Johnston RL. Formula choice: Hoffer Q, Holladay 1, or SRK/T and refractive outcomes in 8108 eyes after cataract surgery with biometry by partial coherence interferometry, J Cataract \& Refract Surg 2011, 37(1); 6371.

16. Abulafia A, Barrett GD, Rotenberg M, Kleinmann G, Levy A, Reitblat $O$, et al. Intraocular lens power calculation for eyes with an axial length greater than $26.0 \mathrm{~mm}$ : Comparison of formulas and methods. J Cataract Refract Surg. 2015 Mar; 41 (3): 548-56.

17. Bang S, Edell E, Yu Q, Pratzer K, Stark W. Accuracy of intraocular lens calculations using the IOL Master in eyes with long axial length and a comparison of various formulas. Ophthalmology, 2011 Mar; 118 (3): 503-6.

18. Ghanem A A, ElSayed H M. Accuracy of intraocular lens power calculation in high myopia. Oman J Ophthalmol. 2010 Sep-Dec; 3 (3): 126-130.

19. Mitra A, Jain E, Sen A, Tripathi S. A study regarding efficacy of various intraocular lens power calculation formulas in a subset of Indian myopic population. Indian J Ophthalmol 2014 Jul; 62 (7): 826-828.

20. El-Nafees R, Moawad A, Kishk H, Gaafar W. Intraocular lens power calculation in patients with high axial myopia before cataract surgery. Saudi Journal of Ophthalmology, 2010; 24: 77-80.

21. Shah SP, Jadoon MZ, Dineen B, Bourne RR, Johnson GJ, Gilbert CE, et al. Refractive errors in the adult Pakistani population: the national blindness and visual impairment survey. Ophthalmic Epidemiol. 2008 MayJun; 15 (3): 183-90.

22. Fricke TR, Jong M, Naidoo KS, et al. Global prevalence of visual impairment associated with myopic macular degeneration and temporal trends from 2000 through 2050: systematic review, meta-analysis and modelling. Br J Ophthalmol. 2018; 102 (7): 855-862. 